\title{
К ВОПРОСУ О РАЗГРАНИЧЕНИИ ПОНЯТИЙ «ИНТЕГРАЦИЯ», «СОТРУДНИЧЕСТВО», «ПАРТНЕРСТВО» В КОНТЕКСТЕ ИНИЦИАТИВЫ «ОДИН ПОЯС, ОДИН ПУТЬ» (НА ПРИМЕРЕ РОССИИ И КИТАЯ)
}

\section{IN REFERENCE TO DIFFERENTIATION OF THE TERMS «INTEGRATION», "COOPERATION", "PARTNERSHIP» UNDER THE BELT AND ROAD INITIATIVE (A STUDY OF RUSSIA AND CHINA)}

A. Iambaev

Summary. The article is devoted to analysis and differentiation of the terms: integration, cooperation and partnership, used in the texts of Russian-Chinese international legal acts, which are aimed at establishing relations between states, including relations within the Belt and Road Initiative, launched by China. The author emphasizes significance and prospects of the initiative under discussion, and states close bilateral relations between Russia and China in the field of political and economic interaction. Using the example of the international acts, mentioned above, which determine that kind of interaction, the author reveals uncertainty in the terms' definitions and finds important to focus on using the terms in economic and legal discourse. The article quotes the words of a number of researchers who studied the definitions of the terms separately, as well as through each other, and who explored the similarity and differences of the terms' meanings. The author comes to the conclusion that there are special aspects in theoretical understanding of terms, which influence on the practical ways of using the terms, and admits justifiability of using the terms in the texts of Russian-Chinese international legal acts, confirming this with political and economic relations background of the states.

Keywords: Russian-Chinese interaction; Belt and Road Initiative; Silk Road Economic Belt; Russian-Chinese Joint Statement; international relationships; integration; cooperation; partnership; word etymology; terms' meanings differentiation.
$\mathbf{H}$ а современном этапе развития международных отношений российско-китайское взаимодействие приобрело особую актуальность. Несмотря на общий рост напряженности в мире, нагнетание атмосферы соперничества между крупными державами, Российская Федерация и Китайская Народная Республика продолжают плодотворно сотрудничать в практических областях и на международной арене, являясь, как это не раз отмечалось главами названных государств, добрыми соседями и равноправными партнерами [10].
Ямбаев Алексей Анатольевич

Аспирант, Байкальский государственный университет, г. Иркутск iambaev.al@mail.ru

Аннотация. Статья посвящена анализу и разграничению понятий интеграция, сотрудничество и партнерство, используемых в текстах международно-правовых актов России и Китая, целью которых является установление определенных отношений государств, в том числе, в рамках экономической инициативы Китая «Один пояс, один путь». Автором подчеркивается актуальность и перспективность названной инициативы, а также констатируется тесная связь России и Китая в области политико-экономического взаимодействия. На примере конкретных международных актов, определяющих такое взаимодействие, выявляется неоднозначность использования исследуемых в статье понятий, необходимость обращения к их определениям и примерам использования понятий в экономико-правовом дискурсе. В статье приводятся мнения исследователей, изучавших вопросы определения понятий интеграция, сотрудничество и партнерство в отдельности, а также друг через друга, близость их значений и различия. Автор приходит к выводу о наличии особенностей теоретического понимания дефиниций, которые должны обосновывать выбор использования понятий на практике, на основе чего признает оправданность их применения в текстах приводимых международно-правовых актов России и Китая, подтверждая это сложившимся опытом политических и экономических взаимоотношений стран.

Ключевые слова: российско-китайское взаимодействие; Один пояс, один путь; Экономический пояс Шелкового пути; совместное заявление России и Китая; международные отношения; интеграция; сотрудничество; партнерство; этимология слова; разграничение понятий.

Безусловно, на сегодняшний день основным направлением такого межгосударственного взаимодействия является торгово-экономическое сотрудничество, поскольку придание экономическому развитию особой динамики является первостепенной задачей мирового сообщества в условиях кризисных периодов [3].

В этой связи нельзя не отметить набирающий темп мегапроект - китайскую экономическую инициативу «Один пояс, один путь», посвященную созданию тран- 
севразийских торговых коридоров, участие в которой видит перспективным и взаимовыгодным более 70\% государств в мире и значительное число международных организаций [13].

Россия также находится в числе участников данной инициативы. Тесное взаимодействие России и Китая в этом контексте подтверждается двусторонними соглашениями, подписанными главами двух государств.

Так, 8 мая 2015 года подписано «Совместное заявление Российской Федерации и Китайской Народной Республики о сотрудничестве по сопряжению строительства Евразийского экономического союза и Экономического пояса Шелкового пути» [11]. Документ, в соответствии с названием, положил начало объединению Евразийского экономического союза (ЕАЭС, бывшего ЕврАзЭС), включающего в состав Российскую Федерацию, Республику Казахстан, Республику Беларусь, Кыргызскую Республику и Республику Армения, с подпроектом инициативы «Один пояс, один путь» — «Экономическим поясом Шелкового пути», посвященным построению сухопутных экономических коридоров в разные точки Евразии.

Кроме того, 5 июня 2019 года было подписано «Совместное заявление Российской Федерации и Китайской Народной Республики о развитии отношений всеобъемлющего партнерства и стратегического взаимодействия, вступающих в новую эпоху» [10]. Данное заявление было в том числе посвящено 70-летию дипломатических отношений между странами. В тексте заявления отдельным пунктом выделяется поддержка Китая в инициативе «Один пояс, один путь».

Согласно анализу содержания названных международно-правовых актов, Россия и Китай выразили намерения по дальнейшему сопряжению евразийской экономической «интеграции», наращиванию регионального «сотрудничества» и углублению отношений всеобъемлющего «партнерства». При этом приведенные слова: интеграция, сотрудничество и партнерство, а также включающие их словосочетания, упоминаются в заявлениях неоднократно, а именно - 9, 118 и 14 раз соответственно, в совокупности двух документов.

Представляется, что в некоторых случаях понятия используются в текстах актов исключительно в качестве фигуры речи в целях подчеркивания уровня отношений между акторами (субъектами) на внешнеполитической арене.

Отсутствие конкретного нормативного наполнения указанных понятий усложняет понимание качества и дальнейших перспектив развития международных отношений, регулирование которых ставится целью подписания Совместных заявлений. Как следствие, это влечет за собой необходимость изучения определений данных понятий и разъяснения их разграничения.

В литературе данные вопросы являются дискуссионными, что, прежде всего, обусловлено наличием зачастую абсолютно разных подходов к определению заданных категорий международного права ввиду их комплексной, междисциплинарной и динамической природы.

Так, по мнению Воронцовой Н.А., интеграция - это «процесс взаимодействия в международной экономической системе публичных и частных лиц с целью установления расширенного экономического пространства». Также автор отмечает, что интеграция, исходя из этимологии слова, является и оценочной категорией, описывающей цель реализации интеграционных процессов - «создание интеграционного объединения»; в совокупности названных качеств интеграции, в отличие от сотрудничества, отличающегося координирующим (направляющим) акцентом в торговых отношениях, свойственен метод субординации, которому присущи элементы надгосударственности - к примеру, в создании «специальных органов международного правосудия». Более того, разграничивая сотрудничество и интеграцию, автор выделяет «количественное и качественное отличия в полномочиях международных организаций», указывая, что в интеграционных процессах формируется особый режим движения капитала, товара, рабочей силы, а также происходит «взаимопроникновение и слияние государственных интересов» [2].

Лабин Д.К., ссылаясь на то, что при интеграции происходит «добровольное ограничение суверенитета государств», полагает, что сотрудничество не влияет на суверенитет государства [8], то есть, по существу, оно предполагает условно более свободное межгосударственное взаимодействие, и это является отличительной чертой сотрудничества.

Цыганков П.А. в данном вопросе приходит к выводу, что сотрудничество следует рассматривать как «процесс взаимодействия двух или нескольких акторов, в котором ... доминируют совместные поиски реализации общих интересов, ... взаимной координации политик, обеспечивающий определенные взаимные выгоды». Автор обращает внимание на то, что сотрудничество и интеграция как термины все чаще разводятся - если межгосударственное сотрудничество не распространяется за рамки, ограниченные суверенитетом страны, то интеграция, напротив, означает передачу части суверенитета в общее согласованное управление инте- 
грируемых государств. При этом интеграция трактуется как «процесс образования целостности из элементов или частей», при котором предполагается появление «какого-то нового качества, не тождественного простой сумме элементов», в современном представлении - появления суперструктуры межгосударственных объединений. Сотрудничество же, напротив, «не предполагает создание целостности, а лишь реализацию некоего общего интереса» [12].

Далее, перемещая исследуемый вопрос в плоскость «международного партнерства», следует отметить позицию Ковальковой Е.Ю., которая, обращаясь к важности развития сотрудничества между государствами, в частности - экономического, «на основе равенства и обоюдного удовлетворения интересов партнеров», полагает, что межгосударственные отношения, именуемые партнерскими (партнерством), обладают иным качеством по сравнению с традиционным сотрудничеством. В названных условия взаимодействия, по мнению автора, «субъектами и адресатами международно-правовых предписаний становится вся масса хозяйствующих субъектов», а роль государства «сужается и сводится лишь к выработке оптимальных юридических условий для самостоятельной и эффективной внешнеторговой и внешнеэкономической деятельности», происходит перенос акцента в сотрудничестве на экономический уровень [7].

Государев М.А., рассуждая о критериях разграничения партнерства и сотрудничества, отмечает, что ими могут стать долгосрочность и глубина развития отношений между государствами [4].

В то же время Новиков И.А. определяет партнерство через сотрудничество, подчеркивая, что в этом случае наличие выгодных каждой стороне отношений презюмируется, более того, интересы партнеров должны совпадать или, как минимум, проходить согласование [9].

В дополнение к вышеизложенной дефиниции Жеглова Ю.Г. полагает необходимым отметить, что партнерство выглядит «как довольно гибкий формат межгосударственных отношений при понимании с обеих сторон неизбежности долгосрочного сосуществования и сотрудничества, соответствующего национальным интересам каждой из сторон» [6].

Не умаляя существование вышеприведенных точек зрения и по большей части соглашаясь с ними, стоит отметить, что в нормативном аспекте «интеграция», «сотрудничество» и «партнерство» - явления международного взаимодействия государств-участников, каждому из которых в теоретическом понимании присущи свои особенности.
Так, интеграции, как наиболее сложной форме такого взаимодействия, присущи, среди прочего, взаимопроникновение и переплетение национальных процессов, на основе которых в последующем происходят глубокие структурные изменения в экономике государств-участниц, появляется необходимость целенаправленного урегулирования взаимосвязанных процессов, создания надгосударственных структур.

В свою очередь сотрудничество, прежде всего, базируется на принципах независимости, соблюдения национального суверенитета государственных образований и обеспечения взаимной выгоды его участников.

В то же время основными составляющими «партнерства», позволяющими отграничить его от других типов международных отношений, являются продолжительный характер взаимодействия, общность целей, задач, интересов, глобальность уровня возникновения, надежность, складывающаяся из готовности сторон учитывать интересы друг друга и партнерства в целом как свои собственные, наличие действенных механизмов реализации более тесного сотрудничества.

Как представляется, вышеизложенные основные черты анализируемых понятий в целом позволяют понять смысловую направленность их использования в содержании международно-правовых актов.

Однако, учитывая специфику рассматриваемых отношений, в большинстве случаев фактическое отражение анализируемых явлений в соответствующих документах варьируется в зависимости от конкретных участников отношений, действующего положения дел на политической арене, задачах взаимодействия. К примеру, не всегда факт указания сторонами-участниками на наличие партнерских отношений свидетельствует о реальности таких отношений в нормативном их понимании (отношения стратегического партнерства России и Сербии как демонстрация близости стран и поддержки сильной стороной слабой стороны) [5]. Совокупность данных обстоятельств также необходимо принимать во внимание при оценке качества и перспектив развития тех или иных межгосударственных отношений.

Возвращаясь к анализу положений ранее приведенных Совместных заявлений, с учетом теоретического осмысления исследуемых явлений, представляется, что наличие в текстах названных документов понятий «интеграция», «сотрудничество», «партнерство» вполне оправдано.

На сегодняшний день взаимодействие России и Китая можно описать отношениями добрососедской близости с учетом увеличения количества экономических 
контактов и разрастанием двустороннего сотрудничества. В частности, как отметил советник департамента Евразии Министерства иностранных дел Китайской Народной Республики Юй Цзунь в ходе выступления в рамках форума развития инвестиционного сотрудничества в сентябре 2018 года, Россия остается самым важным партнером Китая по инициативе «Один пояс, один путь» [1], представляющей собой глобальную Евразийскую экономическую интеграцию, в рамках которой реализуются два обширных экономических инфраструктурных проекта, составляющих основу инициативы,- «Экономический пояс Шелкового пути», а также «Морской
Шелковый путь XXI века», соотносимый по своим задачам с сухопутным маршрутом, но ориентированный на «морскую» направленность торговых путей.

Кроме того, нахождение России и Китая под санкционным давлением со стороны западных стран привело к существенному повышению уровня доверия и взаимной поддержки между государствами, что, безусловно, свидетельствует о улучшении их политических взаимоотношений, позволяющем применять в текстах правовых актов такие выражения, как, например, «всеобъемлющее взаимовыгодное сотрудничество и партнерство».

\section{ЛИТЕРАТУРА}

1. В Китае назвали Россию главным партнером инициативы «Один пояс, один путь». [Электронный ресурс].- Режим доступа: https://ria. ru/20180915/1528631341.html (дата обращения: 17.03.2021).

2. Воронцова Н.А. Правовые основы становления и функционирования межгосударственного механизма интеграционных процессов в Евразийском экономическом сообществе: Автореф. дис. докт. юрид. наук.—М., 2004.—С. 12.

3. Выступление и ответы на вопросы СМИ Министра иностранных дел Российской Федерации С.В. Лаврова в ходе пресс-конференции по итогам совещания министров иностранных дел государств-членов Шанхайской организации сотрудничества в формате видеоконференции, Москва, 13 мая 2020 года. [Электронный ресурс].— Режим доступа: https://www.mid.ru/foreign_policy/news/-/asset_publisher/ckNonkJE02Bw/content/id/4121622 (дата 06ращения: 15.03.2021).

4. Государев М.А. Анализ развития форм межфирменных отношений // Экономический анализ: теория и практика. — 2006.— № 2 (59). —C. 39.

5. Декларация о стратегическом партнерстве между Российской Федерации и Республикой Сербией от 24 мая 2013 года. [Электронный ресурс].— Режим доступа: http://www.kremlin.ru/supplement/1461 (дата обращения: 12.03.2021).

6. Жеглова Ю.Г. Стратегическое партнерство как формат межгосударственных отношений // Контуры глобальных трансформаций: политика, экономика, прав0.-2014.-Выпуск 3.-С. 116-117.

7. Ковалькова Е.Ю. Сотрудничество и партнерство между Российской Федерацией и Европейским союзом: правовые аспекты: Автореф. дис. канд. юрид. наук. — Казань, 2001.—C. 12-13.

8. Лабин Д.К. Международно-правовое обеспечение мирового экономического порядка: Автореф. дис. докт. юрид. наук. — М., 1993.—С. $24-25$.

9. Новиков И.А. Отношения России и Европейского союза: проблемы и факторы развития стратегического партнерства: Автореф. дис.канд. полит. наук.Санкт-Петербург, 2011.-С. 10-11.

10. Совместное заявление Российской Федерации и Китайской Народной Республики о развитии отношений всеобъемлющего партнерства и стратегического взаимодействия, вступающих в новую эпоху от 05.06.2019. [Электронный ресурс].— Режим доступа: http://www.kremlin.ru/supplement/5413 (дата 06ращения: 17.03.2021).

11. Совместное заявление Российской Федерации и Китайской Народной Республики о сотрудничестве по сопряжению строительства Евразийского экономического союза и Экономического пояса Шелкового пути от 08.05.2015. [Электронный ресурс].— Режим доступа: http://kremlin.ru/supplement/4971 (дата обращения: 17.03.2021).

12. Теория международных отношений: учебник для академического бакалавриата / под редакцией П.А. Цыганкова.— Москва: Издательство Юрайт, 2019.- C. 246-247.

13. 已同中国签订共建 “一带一路” 合作文件的国家一览. [Электронный ресурс].— Режим доступа: https://www.yidaiyilu.gov.cn/gbjg/ gbgk/77073.htm (дата обращения: 10.03.2021).

(с Ямбаев Алексей Анатольевич ( iambaev.al@mail.ru ).

Журнал «Современная наука: актуальные проблемы теории и практики» 